\title{
La funcionalidad de un espacio: la frontera granadina en el siglo XV
}

\author{
Fernando Castillo Cáceres
}

RESUMEN

Durante el siglo XV y hasta el reinado de los Reyes Católicos, la frontera granadina y el propio reino nazarí adquieren un acentuado carácter funcional para la monarquía y el conjunto de la sociedad castellana, to cual permite aventurar que su existencia resultaba mas ventajosa que su conquista. El reino granadino, que en esta época distaba de constituir una amenaza seria, se convierte en un recurso político y económico al que acudía periódicamente la monarquía.

Suponia una inestimable fuente de ingresos para la corona gracias a las parias y a los servicios votados por las Cortes, pero también era un medio para fortalecer el poder real e incrementar el prestigio regio. Así mismo, los conflictos de baja intensidad y carácter limitado emprendidos contra los nazaríes permitían unir al reino en una guerra justa al tiempo que distraer las energías y ambiciones nobiliarias. Por otra parte, este grupo social encontraba en la frontera la oportunidad de satisfacer las exigencias propias del espiritu de la
Para Amparo, mi madre.

Para Fernando y Diego, mis hijos.

\section{ABSTRACT}

The Granadian border and the nazari kingdom itself had an important functional status for the monarchy and the Castillian society during the $X V t h$. Century up to the Reyes Catolicos accession.Due to that fact its mere being was worth than its conquest. At the time, the nazari kingdom was not a serious threat and it became a political and economical resource for the monarchy: it was an invaluable source of incomings for the Crown owing the parias and the other taxes, but it also was a way of enhacing the power and the prestige of Castillian Monarchy. The occasional campaings against granadians played an important role by joining the Castillian into a fair war and diverting the ambition of the nobility satisfying at the same time their eagerness distinctive to knigthood spirit. Therefore it could be stated that the anachronic survival of the nazari during the $X V$ th. Century was due not only to the political and 
Caballería y de Cruzada. Se puede aventurar, por tanto, que la sorprendente supervivencia del reino granadino en el siglo $\mathrm{XV}$, hasta resultar un anacronismo

historico, obedeció tanto a la crisis política e institucional de Castilla como a las ventajas derivadas de su existencia para el conjunto de la sociedad. institutional crisis of Castilla but to the obvious advantages of its existence for the society as a whole.

La revitalización bélica de la frontera granadina tras la campaña emprendida por el infante don Fernando en la primera década del siglo XV, que culmina con la toma de la importante plaza de Antequera, supone algo mas que la ruptura de un largo periodo de tregua entre los dos reinos. Significa también la consolidación de una nueva visión de la frontera para los castellanos y, muy especialmente, para la corona, al cobrar un carácter que podriamos denominar funcional y convertirse en un recurso político y económico al que podía recurrir el monarca en tanto persistiera el reino granadino 1 . Desde la primera década del cuatrocientos, cuando ya es evidente que la presencia musulmana dista de ser una amenaza esencial para el reino, tanto la monarquía, la nobleza e, incluso, los grupos no privilegiados, contemplan el espacio de contacto entre los dos reinos y las dos culturas como un lugar idóneo para obtener una serie de ventajas. La condición esencial para ello era que esta vecindad se convirtiera ocasionalmente en un conflicto abierto - definido por la baja intensidad de los combates y por su control esencial al no representar ningún peligro para Castilla- o bien continuara en la frontera durante los periodos de tregua una serie de acciones puntuales, como las escaramuzas y el asedio de fortalezas y plazas, que mantenían el clima bélico y permitían obtener tanto honores como botín. Hay que señalar que estos presupuestos, que no contemplaban la definitiva conquista de Granada, convivían con el tradicional ideal de Cruzada y con un cierto irredentismo surgido en el siglo Xv que tenía como objetivo la finalización de la Reconquista y la recuperación del territorio que constituía el Reino visigodo de Toledo. Estas primeras muestras de una conciencia nacional, muy presente en autores como Juan de Mena ${ }^{2}$, quien puede ser considerado un

\footnotetext{
Hace ya casi tres décadas Miguel Ángel LADERO QUESADA aludió a la «postura peculiar» que mantenía Castilla hacia Granada en el siglo xv, señalando que el largo periodo transcurrido hasta su desaparición es demasiado largo para que sea considerado una simple agonía. (Granada. Historia de un país islámico (1232-1571), Madrid, 1979, pág. 130).

2 CASTIllo Cáceres, Fernando, "El trono de Juan II en el Laberinto de Fortuna", Cuadernos de Historia de España, LXXIV, 1997, págs. 67-98.
} 
adecuado portavoz de las ideas existentes en el entorno cortesano de Juan II ${ }^{3}$, se sustenta en la idea de Reconquista y en el ideal goticista que tiene como referente a la monarquía visigoda, y que en el siglo $x \mathrm{v}$ encuentra un momento favorable para su extensión y unos selectos partidarios que lo respaldan públicamente ${ }^{4}$.

En lo que al especifico desarrollo del conflicto se refiere, hay que señalar que a pesar de que la iniciativa militar a lo largo de la centuria permaneció exclusivamente en manos castellanas, durante los momentos mas intensos del choque entre la nobleza y la monarquía los nazaríes aprovecharon la debilidad del reino, azotado por la guerra civil, para aliviar la presión a la que estaban sometidos. Esto fue lo que ocurrió entre 1446 y 1449 , cuando en toda la frontera, especialmente en la zona este, se produjo una quiebra del sistema militar castellano a causa del recrudecimiento del conflicto que mantenían Alvaro de Luna y parte de la oligarquía nobiliaria. Es en estos momentos cuando se revela claramente como la vida del reino granadino estuvo condicionada durante el Cuatrocientos por la fortaleza o debilidad castellana, según fuera la coyuntura política derivada de la lucha entre nobleza y monarquía ${ }^{5}$. Sin embargo, la considerada casi milagrosa supervivencia de Granada desde la toma de Antequera, cuando ya era evidente su aislamiento internacional y la absoluta superioridad bélica casteIlana ${ }^{6}$, parece que quizás no obedeció únicamente a la pasividad militar de este reino - fruto, por otra parte, de la inestabilidad política y de la crisis institucional que atravesaba- sino que también pudo responder a la inercia derivada de una situación que significaba, según la ocasión, una fuente de ingresos, de prestigio y de afirmación política, resultando mas útil para la

3 A este respecto señala José Manuel NiETo Soria que Juan de Mena fue un agente mas de la propaganda política monárquica junto a los poetas cortesanos y los artistas. ("Propaganda poIítica y poder real en la Castilla Trastamara: una perspectiva de análisis", Anuario de Esfudios Medievales, 25, 1995, págs. 513 y ss).

4 En relación con este asunto, se puede consultar, entre otras, las obras de José Antonio Maravall, "El concepto de Monarquía en la Edad Media Española», Estudios de Historia del Pensamiento Español, I, Madrid, 1983, págs. 77 y ss , «La idea de Reconquista en España durante la Edad Media», Estudios sobre Historia de España, edición de Manuel Fernández Alvarez, Madrid, 1965 ; de Ottavio di CAMILLO, El humanismo castellano del siglo XV, Valencia, 1976; de Ángel Gómez Moreno, España y la Italia de los humanistas, Madrid, 1994; de José Manuel NiETo SonIA, Fundamentos ideológicos del poder real en Castilla (siglos XII-XVI), Madrid, 1988; de Emilio MITRE FeRnÁndeZ, « ¿Un sentimiento de comunidad Historia de España Menéndez Pidal,Tomo XVI, Madrid, 1994; hispánica? La historiografía peninsular", La época del gótico en la cultura española(c. 1220-c.1480), Historia de España Menéndez Pidal,Tomo XVI, Madrid, 1994.

5 Ladero Quesada, ob.cit. pág. 131

6 En relación con la superioridad militar castellana, resulta muy ilustrativo lo ocurrido con la artillería, un arma que se reveló decisiva con los Reyes Católicos y que fue empleada ya por el Infante don Fernando en la campaña de 1410, pero que los nazaries no poseían, lo cual también da idea del atraso técnico de los granadinos en cuestiones militares. (lbídem, págs. 173 y 174). 
monarquía el mantenimiento de un estado vasallo bajo control que su conquista definitiva.

Hasta mediados del siglo XIV, guerra y frontera constituian una realidad muy diferente de lo que habían de ser después de esas fechas. A lo largo de los trescientos años anteriores al reinado de Pedro I, los reinos peninsulares estuvieron determinados por el mundo musulmán, siendo la defensa o la expansión del espacio de contacto entre ambos la razón de ser de su existencia. Esta actividad esencialmente bélica, en ocasiones ofensiva y en otras defensiva, fue durante este periodo la principal función de las monarquías hispánicas, en especial de las occidentales, y es tan acusada esta característica que ha llevado a que se les califique de «reinos-frontera»? Sin embargo, desde el ultimo tercio del siglo XIII estas entidades políticas dejaron de estar condicionadas por unas posibles amenazas a su existencia procedentes de la frontera, limitada ahora al reino de Granada, por lo que se inicia lo que puede considerase un proceso de integración de este espacio en la vida política castellana, el cual deja de constituir un objetivo político prioritario. Este proceso está unido al desarrollo de largos periodos de treguas entre los dos reinos, los cuales suponen una fuente de ingresos para la monarquía castellana gracias al pago de las parias, asi como una garantía de paz para los granadinos y una intensificación de los contactos entre las dos culturas, ya de por si estrechos. De esta forma a lo largo de la segunda mitad del siglo x.ı la frontera dejó de ser contemplada en la vida política castellana como una zona de la que provenían amenazas contra su supervivencia, quedando asimilada, por no decir institucionalizada, como un elemento mas, característico del reino, que permitía mantener vivo el ideal de cruzada y a la corona obtener unos ingresos excepcionales por su carácter y cuantía.

Este panorama se enriqueció, aunque conservando las características esenciales señaladas, desde que tuvieron lugar las campañas granadinas del Infante don Fernando entre 1407 y $1410^{\circ}$, gracias a las cuales se produjo un redescubrimiento de la utilidad de la frontera, al que no era ajeno

\footnotetext{
7 Ayala, Carlos de, "Las Ordenes Militares castellano-leonesas y la acción de frontera (siglos XIII-XIV)", conferencia en la Mesa Redonda sobre Identidad y representación de la frontera en la España Medieval (siglos XI-XIV), celebrada en Madrid en diciembre de 1998.

8 Un resumen de las campañas granadinas del Infante don Fernando se puede ver en la obra citada de Miguel Ángel Ladero QUeSADA (págs. 133 a 135), así como en el ya clásico trabajo de Luis SuÁRez FeRnández, Los Trastamaras de Castilla y Aragón, tomo XV, Historia de España, Ramón Menéndez Pidal, Madrid, 1970, o en el reciente trabajo de Pedro A. PorRAs ARBOLEDAs, Juan II (1406-1454), Palencia, 1995. Así mismo, existe una rica información en la Crónica de Juan 11, (ed Juan de Mata Carriazo y Arroquia, Madrid,1982), de Alvar García DE SANTA MARíA, quien detalla de forma pormenorizada los distintos episodios de la guerra.
} 
el desarrollo de las ideas de la Caballería durante el Cuatrocientos y el choque de la monarquía - una institución que experimentaba un accidentado pero firme avance en la afirmación de su autoridad - con las pretensiones nobiliarias de orientar a su favor la constitución política del reino. Desde este momento, tanto el reino nazarí como el espacio de contacto con el mismo se contempla en Castilla no solo como una fuente de riqueza y de ascenso social para todos los grupos sociales - algo ya sabido, sino también como un medio para el desarrollo de la vida caballeresca y el reforzamiento del prestigio y la autoridad regia.

El reino granadino ofrecía al monarca la posibilidad de llevar a cabo lo que se consideraba una guerra justa, lo cual le permitía a su vez subordinar a la nobleza y a las ciudades a su autoridad al vincularles a una iniciativa a la que no se podían sustraer y que reforzaba su posición. Es evidente que todo ello constituía una verdadera campaña de propaganda política dirigida a la exaltación de la figura real ${ }^{9}$. Conviene recordar en este punto el papel de precursor desempeñado por en Infante don Fernando, quien en 1410, tras alcanzar el sonado éxito que supuso la toma de Antequera, realizó una verdadera entrada triunfal en Sevilla, a la que siguió otra mas discreta pero no menos efectista en Valladolid. En la ciudad andaluza, don Fernando pudo comprobar los efectos de su victoria en el reino y la reacción ante el esplendor de la comitiva en la que figuraban los caballeros que habían participado en la campaña, unos moros cautivos y la espada de Fernando III, finalizando con un Te Deum en la iglesia de Santa María la Mayor. Como un cónsul o un emperador romano, el Infante protagoniza el éxito alcanzado y pone de relieve la importancia, ya un tanto olvidada, que tenían las victorias sobre los musulmanes en términos políticos ${ }^{10}$.

La memoria que debió quedar de estos fastos en la sociedad castellana contribuye a que se entienda mejor la entrada triunfal de Juan II en Toledo el 28 de agosto de 1431, tras haber obtenido la victoria de la Higueruela, en lo que constituye un importante acto de propaganda monárquica que recoge los frutos de un éxito militar contra quienes son considerados ante todo

9 En lo referente a esta cuestión, hay que tener presente que la propaganda fue una practica habitual en la vida política castellana durante el siglo $\mathrm{xv}$, adoptando formas variadas y aprovechando los diferentes medios a su alcance. NiETo SORIA, José Manuel, «Apología y propaganda de la realeza en los cancioneros castellanos del siglo XV. Diseño literario de un modelo político". En la España Medieval, 11, 1988, pág.196. Sobre la propaganda de la monarquía en el Cuatrocientos, se puede ver también de este autor, Fundamentos ideológicos del poder real en Castilla (siglos XIIIxvi), Madrid,1988, así como la anteriormente citada «Propaganda política...».

10 Ciertamente, este acto recuerda inevitablemente a otros protagonizados por héroes de la Antigüedad, los cuales probablemente eran conocidos en la época gracias entre otros a Tito Livio. Los datos acerca de estas entradas triunfales los podemos encontrar en la crónica de Alvar García DE Santa María (ob. cit. cap. 189 , pág. 416 y cap. 200 , págs. $398-400$ ). 
enemigos de la fe ${ }^{11}$. El rey castellano, una vez que habia disfrutado en Córdoba de un primer baño de multitudes, se dirigió a la ciudad del Tajo donde recibió una apoteósica bienvenida por parte de la población de la capital toledana, ricamente engalanada para la ocasión. Así mismo, se celebraron una serie de actos que constituyen una ceremonia a la vez civil y religiosa, durante la cual se desplegó un intenso providencialismo que muestra el espíritu de cruzada existente en la sociedad, como se desprende de la intervención del alcalde Gonzalo Fernández y del ofrecimiento por parte de Juan II de sus pendones en la Catedral. Parece evidente que la figura regia obtuvo de todos estos actos, celebrados precisamente en una de las ciudades mas importantes del reino, un robustecimiento de su prestigio y un reconocimiento de su autoridad sobre otras instancias al aparecer como artífice de la victoria sobre los granadinos y como encarnación de la máxima potestad del reino. A este respecto, hay que recordar que este tipo de actos fueron una practica habitual en la vida política castellana durante el siglo $x V$, adoptando formas variadas y aprovechando cualquier medio a su alcance. Por otra parte, es la monarquía y no la nobleza quien posee la legitimidad que le permite identificarse con una empresa que constituye, al menos teóricamente, lo que podriamos denominar una razón de estado y una guerra justa.

Durante el siglo xv parece existir una coincidencia general en distinguir entre los conflictos internos que agitaban al reino - los cuales suscitaban un profundo rechazo, como se desprende del testimonio de Juan de Mena al referirse a la pugna entre la nobleza y la monarquía- y aquellas otras empresas externas emprendidas contra los infieles. Estas últimas, al unir al reino y extender la fe cristiana, adquieren la consideración de guerra justa, una cualidad reservada esencialmente a las sostenidas contra los musulmanes, contempladas como una actividad misionera, es decir, como una Cruzada. Esta distinción, que constituye el armazón de la teoría de la guerra justa y que arranca de San Agustín, tuvo un amplio eco en la Castilla del siglo $x V^{12}$. En este sentido, la presencia del reino nazari ofrecía a la monarquía la posibilidad de emprender una empresa prestigiosa que además se contemplaba como un cumulo de ventajas.

A este respecto, era un lugar común desde la Antigüedad considerar a las guerras externas como un medio idóneo para emplear las energías de

11 Este acontecimiento aparece relatado en la Crónica del Halconero (Madrid, 1946, ed. Juan de M. Carriazo, cap. C, págs. 110 y ss.). Así mismo, se pueden encontrar referencias al respecto en la Refundición del Halconero (Madrid, 1946, ed. Juan de M. Carriazo, caps. LXVI y LXVII, pág. 124) y en la Crónica de Juan // (Madrid, 1953, ed. de Cayetano Rosell, BAE, pág. 500).

12 Castillo Cáceres, ob. cit. págs. 75-77. 
la nación y como una fuente de virtudes, mientras que la paz se contemplaba como el origen del relajo que engendra todos los vicios ${ }^{13}$. Esta idea benéfica de la guerra estaba muy extendida durante el siglo $x v$ y era compartida por autores como Rodrigo Sánchez de Arevalo, el cual afirmaba que era obligación del monarca «mudar la paz deshonesta en justa discordia y guerra loable" ${ }^{14}$, o el propio Enrique IV, quien en las Cortes de Cuellar de 1454 se dirigió a los representantes de los tres estados resaltando los peligros que representaban la paz y el ocio para el reino, de acuerdo con la tradición clásica. Conforme con lo allí expresado, para este monarca, en el fondo poco dado a las experiencias bélicas, la guerra contra los infieles era una fuente de virtudes publicas y privadas, al contrario que la paz, considerada un periodo desaconsejable que incita a laborar por los intereses particulares y a descuidar el ejercicio de las armas ${ }^{15}$. No resulta descabellado sugerir que las palabras del rey, recogidas precisamente por Enríquez del Castillo, el cronista oficial siempre preocupado por salvaguardar la imagen regia, constituyen una retórica que conecta con el sentir común de la sociedad castellana, es decir, una suerte de langue de bois medieval encaminada tanto a justificar la guerra a partir de los criterios al uso, como a dotar a Enrique IV de cierta belicosidad y de algún rasgo propio del espíritu de Cruzada.

Vemos, por lo tanto, que la guerra contra Granada no solo ofrecía a los monarcas castellanos la posibilidad de obtener las ventajas derivadas del ejercicio de una guerra justa y de satisfacer los anhelos de cruzada, distrayendo de esta forma las aspiraciones de la nobleza, sino que también les brindaba la oportunidad de mostrar su compromiso con la idea de reconquista y de recuperación territorial del reino visigodo de Toledo, unas aspiraciones ampliamente compartidas en el siglo $\mathrm{xv}$ como hemos podido

13 En lo que se refiere a esta cuestión, se puede citar a Flavio Vegecio, quizás el autor clásico mas popular durante la Edad Media y autoridad indiscutible en cuestiones militares, quien de acuerdo con el modelo ofrecido por Esparta, señala las ventajas de la guerra al ser fuente de todas las virtudes, tanto cívicas como militares, al tiempo que sitúa a la paz en el origen de todos los vicios engendrados por el ocio. (Flavio VEGECIO, Instituciones militares, Madrid, 1988, libro I, cap. VIII, pág. 54).

14 Robert B. TATE, "Arevalo y su Compendiosa Historia Hispánica», en Ensayos sobre la historiografía peninsular del siglo XV, , Madrid, 1970, págs. 77-78.

15 Diego EnRiQuez del Castillo, Crónica de Enrique $\mathrm{V}$, ed. Cayetano Rosell, BAE, Madrid, 1953, págs.104-105 «Entre los varones romanos siempre fue la paz mas peligrosa que la guerra, porque con ella puestos en ociosidad, se dieron mas a los deleites que al exercicio de las armas, y procurando sus particulares intereses, menospreciaron la fama, pospusieron el bien de la patria común, e perdieron el señorio universal del mundo, que como industriosos guerreros alcanzaron e poseyeron. Mientras les tuvo la guerra fueron siempre virtuosos, señorearon la monarquía, vencieron sus enemigos, sostuvieron la república, multiplicaron el bien de ella, e quedaron renombrados". 
comprobar al referirnos a Juan de Mena. Hemos visto con anterioridad como estos presupuestos estaban entrelazados, aunque ahora aparecen también como expresión de una conciencia nacional sustentada en el modelo de monarquía visigoda y en el ideal goticista existente desde el siglo XIII, que encuentra en el Cuatrocientos un momento favorable para su expansión y selectos partidarios para su apología.

El recuerdo de los limites territoriales del reino visigodo toledano actuaba como un referente teórico a la hora de plantear el comienzo de las campañas granadinas al proporcionar un importante armazón argumental y retórico a los reyes castellanos para justificar la ruptura de una tregua y unir a todo el cuerpo social tras la empresa. Son numerosos los ejemplos en los que aparece un irredentismo territorial en relación con el reino nazarí. Entre todos podemos citar el objetivo señalado por Enrique IV en 1454 durante las Cortes celebradas en Cuellar, de recuperar lo que «nuestros antepasados perdieron", aludiendo a "los moros que usurpan nuestra tierra, tomada con gran traición" ${ }^{16}$, o la reivindicación formulada por Rodrigo Sánchez de Arevalo, la cual supera los limites peninsulares al reclamar las provincias del norte de África, consideradas herencia legal de la monarquía visigoda ${ }^{17}$.

Como se puede apreciar mas allá de la retórica del momento, la guerra contra los granadinos coincidía con las ideas dominantes en la época, por lo que su inicio por parte del monarca era en determinadas ocasiones una exigencia ineludible, según se desprende de las palabras de Diego de Valera: «e por todos se acordó que, pues a nuestro Señor había placido dar al Rey tantos e tan grandes aparejos para recobrar la tierra que los moros en España tenían usurpada, en injuria de los Reyes antepasados e del, e de tan noble caballería cuanta en sus Reynos habia, el propósito suyo en les querer facer guerra era sancto e bueno... pues nuestro Señor le había dado grandes tesoros para lo cumplir» ${ }^{18}$. El respaldo divino era un argumento que impulsaba el comienzo de lo que ya hemos visto que se juzgaba era una guerra justa y una Cruzada, al tiempo que servía para explicar las principales victorias contra los musulmanes ${ }^{19}$. Así se deduce

16 Ibidem, cap. VIII, págs. 104-105.

17 TATE, ob. cit. pág. 77.

18 Diego de Valera, Memorial de diversas hazañas, Madrid, 1953, ed. Cayetano Rosell, BAE, cap. III. pág. 4.

19 Una vez mas Juan de MeNA constituye un buen ejemplo de esta actitud cuando se refiere a la batalla de las Navas de Tolosa, entre otros ejemplos, como un «triunfo de grande misterio divino". (Laberinto de Fortuna. Poemas menores, ed. Miguel Pérez Priego, Madrid, 1976, coplas 271-274). 
de lo manifestado por Enrique IV en la citada la reunión de las Cortes en Cuellar, cuando afirma que para emprender la guerra contra los granadinos «tres cosas señaladas son que nos ayudan: la primera, que nos mueve justa causa ; la segunda, que tenemos clara justicia; la tercera, que nuestro propósito es sancto, y el celo de Dios nos guía, cuya causa es que se hace" ${ }^{20}$. A ello hay que añadir la tradicional consideración de la guerra durante la Edad Media - una actividad que, según Allmand ${ }^{21}$, se creía que era especialmente proclive a la intervención divina- como un juicio de Dios en la que las victorias y las derrotas respondían a premios y castigos ${ }^{22}$, y cuyo inicio contra los enemigos de la Cristiandad era una obligación de los monarcas a la que debía sumarse el reino.

Vemos, por tanto, que entre las ventajas que ofrecía la frontera granadina a la monarquía se encuentra la de constituir una empresa y un escenario bélico que vinculaba necesariamente a los principales linajes del reino, participantes del ideal de Cruzada y de los principios de la caballería entre los que la lucha contra los infieles constituye el objetivo primordial. Esta circunstancia ofrecía también la posibilidad de distraer en proyectos externos la agresividad y el potencial de un poderoso grupo social que encuentra en la guerra la razón de ser, lo cual permitía asegurar que durante el periodo que durase la campaña, las huestes nobiliarias no iban a servir de instrumento de presión política ni de amenaza militar a la monarquía.

La frontera era primordialmente el lugar de contacto entre dos sociedades que, junto a etapas de enfrentamiento, en muchos momentos habían atravesado periodos de aculturación de cierta intensidad coincidentes con largos periodos de paz, tal que el comprendido entre 1350 y 1406 . Esta influencia mutua se pone de manifiesto en los reinos cristianos peninsulares en el mudejarismo, quizás la expresión mas acabada y fructífera de estos contactos, y en la maurofília, una moda que está presente en la sociedad castellana durante el siglo xV, aunque tenga antecedentes en siglos anteriores ${ }^{23}$. Esta inclinación hacia lo islámico no era compartida de manera uniforme ni tenia homogeneidad geográfica, pues era mas intensa en círculos cercanos al monarca y mas débil entre la nobleza. En lo que se refiere a los grupos sociales urbanos y campesinos, la situación geográfica

\footnotetext{
20 Enriquez del Castillo, Crónica de Enrique N, pág. 105.

21 Allmand, C, La Guerra de los Cien Años, Barcelona, 1990, págs. 65-67.

22 El carácter de la guerra como juicio divino, tanto contra musulmanes como entre cristianos, se deduce claramente de textos como la Crónica de Alvaro de Luna, un aspecto que ha sido resaltado por autores como Pedro A. PORRAS ARBOLEdAS. (Juan I/ (1405-1454), Palencia, 1995, cap. I nota 23).

${ }_{23}$ MACKAY, Angus, La España de la Edad Media.Desde la frontera hasta el Imperio. Madrid, 1980, pág. 219.
} 
determinaba en gran medida su grado de vinculación cultural con el mundo islámico peninsular, incrementándose de norte a sur hasta llegar a la frontera granadina, donde la permeabilidad y las formas de influencia eran, además de intensas, muy diversas. La maurofilía - especialmente destacable en figuras como Enrique IV y, en menor medida, Juan II y Alvaro de Luna- se convirtió en un arma política de gran valor en el contexto de los conflictos civiles para descalificar a quienes aparecian demasiado tolerantes con los infieles. La oligarquía nobiliaria, como hizo en su día con Pedro I, se reclamó defensora de la religión y criticó la cercanía demostrada por los citados personajes hacia lo islámico y lo judío, aludiendo a sus gustos, a la presencia de individuos de este origen en su entorno y a la tibieza demostrada hacia los granadinos.

Esta actitud - basada en parte en la realidad, pues era evidente la cercanía al mundo musulmán de personajes como Enrique IV, aunque es mucho mas discutible en el caso del Condestable, una figura propicia a desatar todas las calumnias - revela la incompatibilidad existente entre la maurofilia y los ideales de la Caballería, dado que el espíritu de Cruzada, que constituye una de las bases de estos principios, no se aviene con la tolerancia que implican las posturas criticadas. Sin embargo, se puede argumentar que esta actitud nobiliaria es esencialmente retórica y coyuntural y que responde a criterios exclusivos de oportunidad política derivados de la pugna mantenida con la monarquia, pues en la practica los principales linajes señoriales castellanos manifestaban una gran afinidad en sus gustos con el mundo musulmán. No obstante, siendo cierto que la nobleza compartía principios estéticos de origen hispano árabe, presentes por otra parte en la sociedad castellana tras un largo periodo de contacto entre ambas culturas, probablemente no mostraba tanta tolerancia ni sentía tanta atracción hacia lo islámico como aquellos a quienes criticaba. Si tenemos en cuenta detalles como la actitud de profundo desagrado demostrada por la nobleza con ocasión del sorprendente viaje de Enrique IV al Norte de África ${ }^{24}$-realizado en plena campaña contra el reino de

24 En 1456, con ocasión de su presencia en Gibraltar, Enrique IV, tras recibir la visita de! gobernador de Ceuta, ordenó a Gonzalo de Saavedra que regresase con su gente a Algeciras, mientras "acordó de se pasar no solamente en Ceuta mas allende por ver el Reyno de Fez". Esta decisión disgustó enormemente a Gonzalo de Saavedra y a Juan Fernández Galindo, quienes además de advertirle de los peligros del viaje por mar, le señalaron lo poco recomendable que era "pasar con gente estraña mayormente en Reyno de infieles y naturalmente enemigos, y le suplicaban y le requerian que no quisiese hacer tal viaje, del qual aunque con salud saliese, seía dino de gran reprehension de todos los que lo supiesen". El rey hizo caso omiso de la recomendación y partió hacia Ceuta acompañado entre otros de Miguel Lucas de Iranzo, a los que se añadió mas tarde Juan Pacheco. Allí se demoró durante tres días debido al mal tiempo y no pudo llevar a cabo una cacería de leones prevista en tierras del rey de Fez a causa de 10 
Granada en lo que puede considerarse una muestra de orientalismo temprano, claramente recogido por Diego de Valera - cabe concluir que la cercanía cultural que propiciaba la frontera no encontraba mucho eco entre este grupo social de privilegiados y que los principios de la Caballería se imponían sobre otras consideraciones.

En lo que se refiere a la fuente de ingresos que representaba la frontera granadina para la hacienda real castellana, hay que señalar en primer lugar la importancia de los tributos pagados por los nazaries durante los periodos de tregua, los cuales solían ascender a unas doce mil doblas anuales, religiosamente recibidas por el rey excepto cuando carecía de fuerza para exigirlos ${ }^{25}$. La magnitud de estas parias contribuye a explicar porqué a pesar del espíritu de cruzada existente en Castilla y de la abundancia de testimonios que alaban la empresa reconquistadora, el resultado final de las campañas emprendidas era siempre la inevitable tregua, un desenlace que dista de coincidir con el animo expresado. Por el contrario, esta forma de resolver el conflicto y su rápida aceptación por los castellanos permite adivinar, por debajo de la retórica de la defensa de la fe, la avidez por las doblas nazaries acuñadas con el oro africano, atraído a la península gracias a la importancia comercial granadina, el cual, en caso de conquista del reino, acabaría en otras cecas distintas de los troqueles de la Alhambra, que es lo mismo que decir que en manos diferentes de las castellanas ${ }^{26}$. Aunque ha existido tradicionalmente cierta tendencia a sobrestimar estos ingresos, a los que con toda justicia se les ha calificado de "riada aurifera", la realidad es que significaban una considerable aportación a la hacienda real y uno de los principales medios, sino el mas importante, de incrementar la masa monetaria en Castilla a lo largo del siglo $\mathrm{XV}$. Hay que tener en cuenta que esta fuente de ingresos tenía la singular característica de responder a la voluntad del monarca castellano, al contrario de lo que ocurría con los procedentes de los impuestos sobre la lana y el comercio del Cantábrico, sometidos a las fluctuaciones del mercado y a la competencia de los productores ingleses, es decir a razones de indole económica y no política. En el caso del oro nazarí bastaba emprender una campaña o, incluso, el mero anuncio de la ruptura de treguas, para que apareciera la posibilidad de un incremento del dinero recibido, aunque,

inseguro de la situación en el hinterland ceutí, por lo que decidió regresar a Tarifa. (VALERA, ob. cit. cap. $X$, págs. 12-13).

25 LADERO QuesadA, ob. cit., pág. 154.

26 En este sentido, la citada Crónica de Juan // (pág. 484) es muy explícita al señalar como la negativa de los nazaries a pagar las parias exigidas junto a la voluntad tanto del rey como del Condestable, están en el origen de las campañas contra Granada de los años 1430-1431. 
eso si, la sutil y hábil diplomacia granadina tenía que percibir claramente la realidad de la amenaza y que Castilla podía reclamar efectivamente el pago del tributo anual exigido, verdadera garantía de supervivencia para los musulmanes. Desde esta perspectiva, proceder por parte de Juan II o Enrique IV a la conquista de Granada, en caso de que hubieran existido la voluntad, los medios y las condiciones necesarias para ello, suponía acabar con una cómoda fuente de ingresos. La vitalidad de la sociedad castellana y la consolidación de la autoridad real, que tenía como corolario la subordinación política de los grandes, junto con las nuevas directrices políticas que contemplaban como un objetivo esencial la expansión exterior del reino, permitieron durante el reinado de los Reyes Católicos emprender la conquista de Granada en la seguridad de que las nuevas tierras y los ruevos recursos incorporados, ahora que se contaba con la adecuada capacidad para emprender su explotación una vez conquistado, representaban una fuente de riqueza superior a las viejas parias. A pesar de su importancia, estos ingresos no dejaban de ser unas aportaciones extraordinarias, ajenas a la capacidad productiva de Castilla; únicamente pueden contemplarse como el fruto pasivo del potencial bélico y político castellano y de la inversión realizada en el desarrollo de la campaña intimidatoria y en la formación y mantenimiento de la hueste.

Otra vía de ingresos para la monarquía relacionada con las campañas emprendidas contra el reino nazarí, la encontramos en la posibilidad de obtener en las Cortes la votación por los procuradores representantes de las ciudades de unos servicios extraordinarios destinados teóricamente para sufragar la guerra contra los granadinos. A estos ingresos excepcionales se añadían los subsidios solicitados por el rey concedidos por el clero castellano procedentes de sus rentas y las limosnas destinadas a la guerra, si esta recibía del Papa la consideración de Cruzada ${ }^{27}$. Es evidente que no siempre la monarquía empleó estos recursos para alcanzar los fines para los que fueron concedidos, ni el resultado de su uso satisfizo a quienes los pagaron. En algunos casos se desviaron para hacer frente a exigencias de tipo político o militar planteadas a la monarquía en el seno del conflicto mantenido con la nobleza y Aragón, cuando no en ganar voluntades o en llevar a cabo actos propios de una política de prestigio, difíciles de entender por los otorgantes de los servicios. Por otra parte, el descontento de los procuradores también hacía acto de presencia cuando el éxito esperado no acompañaba a la petición o la campaña no se desarrollaba de acuerdo con los plazos y gastos previstos, pero sobre todo el malestar se intensificaba cuando se

27 Ibidem, pág. 181. 
reiteraban las peticiones de dinero por parte del monarca ${ }^{28}$. En cualquier caso, la guerra contra Granada ofrecía la posibilidad de conseguir unos importantes ingresos extraordinarios para la hacienda real a cambio de un compromiso en su empleo difusamente exigible.

Por su parte, la nobleza castellana encontraba en las campañas granadinas una primera ventaja económica, como era la cantidad de dinero recibida del rey en pago por los servicios militares prestados por la mesnada señorial integrada en la hueste real durante la campaña ${ }^{29}$, seguida del posible botín que podía obtenerse de los granadinos. Sin embargo, la principal motivación era la esperanza de conseguir una ampliación patrimonial de sus señoríos gracias a la conquista y posterior repoblación de los nuevos territorios adquiridos así como lograr nuevos títulos nobiliarios que, para quienes no formaban parte de este grupo social, significaba el acceso a la condición señorial. No era una esperanza vana, pues durante el siglo XV existió una estrecha relación entre frontera, promoción nobiliaria y expansión del régimen señorial ${ }^{30}$. En la frontera, en el intenso ambiente que alternaba las brillantes acciones personales con las treguas y las escasas campañas, se daban las ocasiones propicias para alcanzar el rango de caballero por alguno de los métodos al uso ${ }^{31}$. Al mismo tiempo se favorecían las condiciones para el fortalecimiento de la nobleza, como revela el hecho de que recibieran cesiones en señorío de numerosos puntos fortificados hasta tal extremo que las plazas de realengo en la frontera hacia 1480 se reducían a Antequera, la base militar de la que partían todas las expediciones, Tarifa, Quesada, Lorca y Alcalá la Real. El resto pertenecía a las ordenes militares o a la jurisdicción nobiliaria, aunque la hacienda real corriese con los gastos de las tropas que las guarnecían ${ }^{32}$.

A todo lo anterior cabe añadir la posibilidad de ganar fama y gloria que ofrecía la frontera a los caballeros ambiciosos y deseosos de cumplir con

28 Aunque son muy abundantes los testimonios al respecto, resulta especialmente ilustrativo el recogido por Diego de VALERA en relación con una nueva petición de Enrique IV a los procuradores. (ob. cit. cap. VIII, pág. 10).

29 Durante el reinado de Juan II, los grandes contemplan la guerra como un negocio especiaimente rentable y habitual debido a las frecuentes guerras civiles y a las campañas de Granada La sucesión de llamamientos y convocatorias por el rey conseguía reunir a una gran cantidad de nobles que acudían a llamada del sueldo, pagado por el monarca en gran parte con los subsidios votados por las Cortes. (PORRAs ARBOLEDAS, ob. cit. pág. 22).

30 LADERO Quesada, ob. cit. pág. 165.

31 Podían ser armados por el propio rey o por su adelantado, beneficiarse de las generosas concesiones de hidalguía frecuentemente concedidas por los monarcas durante el siglo $x \mathrm{~V}$, o bien proclamarse caballero por el expeditivo sistema de «encabalgarse» sobre la montura del enemigo vencido. (Ibidem, pág.165).

32 Ibídem, pág. 165. 
los preceptos de la Caballería y el espíritu de Cruzada. Hay que recordar que la guerra, y en especial la mantenida contra el infiel, permitía seguir el estilo señorial de vida, siendo considerada un acontecimiento alegre que propiciaba el lucimiento social y el despliegue del lujo y la teatralidad ${ }^{33}$. Para los caballeros, las hazañas militares eran una mas entre las manifestaciones externas de la pompa mundana, como la riqueza y el poder ${ }^{34}$, sobre todo si recordamos que, según el Victorial, la fama estaba considerada una prerrogativa exclusiva de este grupo social, al igual que el amor cortés y la gloria ${ }^{35}$. Aunque entre todos los participantes en las expediciones destacaban los jóvenes hijos de la nobleza, muy inquietos y deseosos de ser nombrados caballeros y lograr prestigio guerrero, también nos encontramos con iniciativas procedentes de personalidades como el propio Condestable Alvaro de Luna. Este, en su ansía de monopolizar la gloria y, sin duda, también el botín, atrajo las criticas de la nobleza por haberse adelantado con su hueste a la entrada de la mesnada real en el reino granadino, poco antes de la Higueruela. A pesar de contar con el consentimiento regio y de argumentar que su intención era, además de dejar libre la cercanía del rey por las murmuraciones existentes, la de "fazer serbicio a Dios e al Rey...e daño en los enemigos de la Sancta Fe", a los grandes no se les escapó la intención de Alvaro de Luna de conseguir los beneficios principales de la guerra ${ }^{36}$. Desde otro punto de vista, la crítica a esta conducta revela que la oportunidades que ofrecía la frontera de alcanzar la gloria debían ser relativamente escasas, entendiéndose así gestos como el realizado por el Condestable de retirar a su hueste para permitir que en un encuentro con los nazaríes acaecido en 1431, pudieran combatir otros nobles y alcanzar su parcela de gloria ${ }^{37}$. El deseo de entrar en combate era en ocasiones muy intenso, sobre todo si el encuentro se prometía excepcional por su magnitud, pues a lo largo de la Edad Media y en especial

33 AlLmAND, ob. cit. pág. 71. Un buen ejemplo de lo señalado lo constituye Lucas de Iranzo, cuya vida en Jaén alternaba la guerra de frontera con la vida cortesana. (Ver Hechos del Condestable don Miguel Lucas de Iranzo, ed. de Juan de Mata Carriazo Arroquia, Madrid, 1940).

34 Serrano de Haro, Antonio, Personalidad y destino de Jorge Manrique, Madrid, 1975, pág. 22.

35 LIDA, María Rosa, La idea de fama en la Edad Media castellana, Madrid,1983, pág. 233.

36. Como puede verse, los argumentos esgrimidos en favor del Condestable son ingenuos pues si el primero es increíble, el segundo no es mas que un disfraz de los deseos de gloria y riqueza que no le pasó inadvertido a nadie, como se deduce de las palabras de la Crónica de Alvaro de Luna cuando afirma «Pues estos apartamientos, que usaba por virtuoso remedio contra los ynbidiosos, estos eran mayor ynbidia a ellos diziendo que el quería aventajarse sobre todos, e que buscaba e tomaba para si las empresas de mayor honra" (Cap. XXXIV, págs. 121 y 122).

${ }_{37}$ "Muy prestamente sacó el Condestable una muy fermosa batalla de gente, e por no darles aquella gloria que entendió que ellos cobdiçiaban, dexó su gente a una parte» (Ibídem, cap. XXXVII, pág. 128). 
desde el siglo XIV, no era fácil participar en un choque que pudiera ser relevante por sus dimensiones y consecuencias. Desde este punto de vista, se entiende mejor tanto el papel desempeñado por el reino granadino, como las palabras dirigidas por Alvaro de Luna a Juan II cuando, en los momentos inmediatos a la Higueruela, le dice "que la batalla que tanto deseaba en las manos la tenía» ${ }^{38}$.

En suma, la guerra contra Granada, cuando se emprendía en optimas condiciones, suponía una fuente de ingresos y de prestigio político para el rey ; de tierras, rentas y jurisdicciones para la oligarquía nobiliaria, y de alcanzar fama y celebridad caballeresca para todos. Para el resto aparecía la posibilidad del botín y del ascenso social. Ante este panorama no es extraño que existiese la voluntad de conservar el reino nazarí, sometido y controlada su vida política, como un enemigo rentable y sin capacidad para amenazar a Castilla mas allá de un afortunado lance fronterizo. Probablemente, y a pesar de lo elevado de los gastos que suponía la realización de cada campaña, en algunos momentos la guerra contra Granada debía compensar a la monarquía debido a la rentabilidad, no estrictamente económica, del conflicto y a que el esfuerzo exigido por la guerra no implicaba grandes sacrificios para el reino, al menos hasta los Reyes Católicos. A pesar de la indudable existencia de un espíritu de Reconquista y de reivindicación territorial, que a veces adquiría connotaciones mesiánicas según se deduce de testimonios como el de Fernan Pérez de Guzman ${ }^{39}$, en ocasiones parece que la perspectiva con que se contemplaba la realidad nazarí permite pensar que estaba descartada la voluntad de su conquista y, por lo tanto, de su desaparición política, aunque existiera una reconocida superioridad militar castellana. Así se deduce de lo expresado por el autor de la Crónica de Alvaro de Luna, quien tras achacar a las intrigas nobiliarias contrarias al Condestable ser la causa del precipitado fin de la campaña y de que no se explotase la victoria de la Higueruela cuando Granada estaba aparentemente a merced de los castellanos, sugiere, una vez ocupadas ciertas zonas, lo recomendable de concluir la guerra con el consabido vasallaje nazari ${ }^{40}$.

\footnotetext{
38 Ibídem, Cap. XXXVIII, pág. 136.

39 Según el señor de Batres, el reino de Granada sobrevivió a las campañas del Infante don Fernando debido a la muerte del rey Martín de Aragón y a la pretensión del castellano a esta corona, siendo todo ello fruto de la voluntad divina: «Sin dubda este noble infante diera fin a la dicha guerra, e tornara a España en su antigua posesión, lanzando a los moros della, e restituyéndola a los Christianos" (Fernan Pérez de GuzMÁn, Generaciones y semblanzas, Madrid, 1953, ed.C. Rosell, cap.XXXIII, pág. 712).

40 «E fue muy grand daño e grand cargo de los que fueron cabsa de lo tal, ca en poco tiempo que el Rey estubiera en el reyno de Granada, tomara la mayor parte del por fuerza o pleytesia, segund el estrecho en que avia puesto a los moros, e la grand vitoria que dellos avía avido" (Crónica de Alvaro de Luna, cap. XL, pág. 142)
} 
A lo largo del siglo xv y, en concreto, durante el periodo que se extiende entre la campaña iniciada por Juan II y Alvaro de Luna en 1430 y las emprendidas por Enrique IV entre los años 1455 y 1459 , no son escasas las manifestaciones que permiten aventurar la consideración funcional de la frontera granadina, en la que coinciden los intereses y los presupuestos ideológicos tanto de la monarquía como de la nobleza. Solo a partir de las operaciones realizadas por Enrique IV en los primeros años de su reinado se alterará un tanto esta perspectiva al desplegar el monarca una novedosa estrategia de desgaste - alejada de los principios militares de la Caballería pero de una concepción mas moderna- que distaba de satisfacer las ansias de gloria y de patrimonio de la nobleza. En los años comprendidos entre 1455 y 1459, el rey castellano aprovechando su superioridad y la táctica granadina de refugiarse en sus fortalezas, llevó a cabo periódicas talas y devastaciones de la vega granadina encaminadas a la debilitación del potencial económico de los nazaríes ${ }^{41}$. A pesar del éxito militar de las incursiones, pues realmente estas expediciones punitivas eran mas dañinas que los encuentros formales entre pequeños contingentes de caballeros de ambos bandos, la nobleza apenas tenía ocasión de lucirse y de satisfacer sus deseos de fama, aunque la posibilidad de conseguir algún botín siempre estuviera presente. De todas formas, esta estrategia desgaste — que a menor escala era habitualmente empleada en los combates fronterizos - resultaba especialmente decepcionante en determinadas ocasiones, como sucedió en 1455 cuando se reunió un potente y vistoso ejercito gracias a los subsidios de la Cruzada, pero al cual Enrique IV no permitió entrar en combate; esta decisión hizo que "los mas de los Caballeros fueran mucho maravillados por no haber visto facer tan grandes aparejos para no hacer mas de lo que se hizo" ${ }^{42}$.

Probablemente, la reacción adversa mostrada por autores como Diego de Valera ante las operaciones llevadas a cabo contra Granada, semejante a las expresadas ante la maurofília de Enrique IV, obedece tanto a motivos políticos procedentes del entorno nobiliario encaminados a desprestigiar al rey, como a un autentico sentimiento de disgusto ante la conducta regia. Así mismo, Valera, para enfatizar las criticas, deja entrever que el desagrado no era una cuestión que afectase solo a los grandes,

41 LADERo QueSADA señala junto a los extremos referidos, la eficacia de la estrategia mantenida por EnriquelV, como se desprende de la imposición de unas onerosas parias al emir Sa'd, consistentes en doce mil doblas anuales y seiscientos cautivos, lo cual significaba una importante fuente de ingresos para el monarca castellano. (ob. cit. pág. 149).

42 VAlERA, ob. cit. cap V, pág. 5. 
sino que alcanzaba a todo el reino al vincular las reticencias de las cortes ante las peticiones económicas del rey con la estrategia llevada a cabo. Esto es lo que se desprende de lo proclamado por los procuradores de las ciudades, quienes creían que el tipo de guerra desarrollada perjudicaba mas a Castilla por los elevados gastos que suponían las campañas, que al propio reino de Granada ${ }^{43}$. Por el contrario, Diego Enríquez del Castillo, capellán y cronista favorable al monarca castellano, justifica la estrategia, aludiendo a la bondad del monarca asegurando que no deseaba arriesgar ninguna vida ${ }^{44}$, lo que dejaba traslucir que era consciente de las críticas existentes y de lo extendido de las mismas. Sea como fuere, la conocida e indudable inclinación que sentía Enrique IV hacia todo lo islámico, la cual no debía ser mucho mas intensa que la de Juan II, y su incapacidad para responder a las exigencias de la Caballería, se unieron a un método de guerra poco estimado y peor considerado desde los valores al uso en la oligarquía señorial castellana, dando como resultado un incremento en su desprestigio. Desde otra perspectiva, el monarca castellano al perseguir esencialmente el desgaste económico del adversario revela una consideración de la guerra que, aunque aparece ciertamente alejada de las concepciones caballerescas, muestra rasgos de cierta modernidad. El hecho de rechazar los gestos, que no la retórica, de grandilocuencia bélica en favor de la eficacia a ultranza, junto a lo que podemos denominar una concepción esencialmente patrimonial y política del ejercito - derivada de una consideración de la hueste como instrumento para alcanzar unos fines políticos y económicos inmediatos- son elementos que ciertamente se alejan de las ideas dominantes sobre la guerra. De todas formas es necesario señalar que, en ningún caso, se puede adivinar en la actitud de Enrique IV la voluntad de ultimar la conquista del reino granadino para poner fin a la reconquista y alcanzar los limites fijados por el goticismo característico en la sociedad castellana. Todo ello acentuaba la distancia que le separaba de una nobleza que, en su aspiración a participar oficialmente en las tareas de gobierno, combinaba la búsqueda de mercedes y

43 «Mandó llamar a los Procuradores, y les dixo que el entendía entrar en tierra moros muy mas poderosamente de quantas veces habia entrado, para lo cual convenia que en sus heynos se repartiesen sesenta cuentos de maravedis ; y como quiera que a los Procuradores este paresciese mucho grave, así por los trabajos pasados, como por ver la forma que el Rey en la guerra tenía, en que conocida la verdad en la guerra pasada muy mayores daños habian rescebido estos Reynos quel Reyno de Granada" (Ibidem, cap. VIII, pág. 10).

44 Afirma ENRÍQUEZ DEL CASTILlo que al monarca castellano " no le plascia que los suyos saliesen a las escaramuzas, ni se diesen batallas, ni combates. E quanto quiera que en las tales entradas se gastaban grandes sumas de dineros, quería mas expander sus tesoros dañando los enemigos poco a poco, que ver muertes y estragos de sus gentes (ob. cit. cap. XII, pág. 107). 
dinero con peticiones de una reforma de las costumbres de la corte y de reanudación de la guerra ${ }^{45}$.

De acuerdo con lo señalado hasta ese momento, no es difícil apreciar la contradictoria perspectiva con que se contemplaba desde la sociedad castellana del Cuatrocientos y sus instituciones al ultimo bastión islámico peninsular. Esta óptica combinaba sino la tolerancia, si la complacencia derivada de una situación controlada y de la que se tenía la certeza de que no constituía una verdadera amenaza, la cual además proporcionaba pingües beneficios, tanto económicos como sociales y políticos, con la persistencia de los ideales de reconquista y de la Caballería. Estos principios, sin embargo,eran teóricamente incompatibles con la permisividad que se desprendía de la política de treguas y de campañas limitadas que permitían la existencia de los nazaríes. La contradicción se resolvía acudiendo cada grupo social a diferentes tipos de argumentos; en el caso de la nobleza, lo habitual era señalar al rey como responsable por no responder a las exigencias de la Caballería y de la religión, utilizando su maurofília como instrumento de descrédito político y de disculpa. Por su parte, el monarca y el circulo de partidarios del poder real situaban la responsabilidad de la supervivencia granadina en la división existente en el reino a causa de las pretensiones de la oligarquía nobiliaria, a la que se acusaba de dedicar la mayor parte de sus energías a rivalizar con el poder real. La realidad es que con la llegada de los Reyes Católicos cambiaron los criterios y el talante político con que se contemplaba al estado musulmán desde prácticamente 1350. Estos monarcas lograron reunir, no sin esfuerzo, los recursos y la voluntad necesarias para llevar a cabo una campaña definitiva contra Granada, la cual se reveló mas costosa de lo imaginado, todo ello en la certeza de que era mas conveniente para el reino la unificación peninsular que el mantenimiento ficticio de un anacronismo político que impedía liberar energías para otras empresas exteriores.

45 Mackay, ob. cit. pág. 222. 